\title{
The Accrual Anomaly: Australian Evidence
}

\author{
Greg Clinch, Damian Fuller, Brett Govendir and Peter Wells
}

18 June, 2009

School of Accounting, University of Technology, Sydney, Broadway NSW 2007, Australia

\begin{abstract}
This paper investigates whether the accrual anomaly identified by Sloan (1996), whereby investors overestimate the impact of accruals on the persistence of earnings exists within an Australian context. While there is general support for the existence of the anomaly in Australia there are a number of idiosyncrasies in the results. First, there is evidence that in Australia investors underestimate the persistence of earnings. Second, there are greater errors in assessing the impact of cash flows on the persistence of earnings than accruals (i.e., a cash flow anomaly rather than an accruals anomaly). Third, returns to the hedged portfolio trading strategy are increasing over the three year period subsequent to portfolio formation. Analysis of these results indicates that they are primarily attributable to a limited number of firm year observations in the extreme positive tail of returns. Additionally, a range of sensitivity tests were undertaken to address the robustness of these results.
\end{abstract}

\section{JEL Classification:}

Keywords : $\quad$ Financial reporting, Accrual anomaly. 


\section{Introduction}

The provision of information for decision making is well recognised as a function of accounting, and the performance measure commonly identified as best satisfying this function is earnings rather than cash flows. While empirical evidence exists to support this proposition (Dechow, 1994), whether the implications of the separate cash flow and accrual components of earnings are fully appreciated by financial statement users is yet to be fully determined. Specifically, Sloan (1996) provides evidence that cash and accrual components of earnings have different implications for the persistence of earnings, however there is evidence that this is not understood by investors and thus systematic mispricing of accruals occurs. This phenomenon has been labeled the accrual anomaly. The objectives of this paper are twofold. First, to provide evidence on whether the results in Sloan, which are based upon US data, are generalisable to Australia. Second, to further investigate whether the accrual anomaly is a consequence of research design. Undertaking the study in Australia provides the advantage of including smaller firms in the sample where it is expected the effects of the anomaly may be more pronounced, and regulation (AASB 1026 Statement of Cash Flows) requires the disclosure of cash flow from operations under the direct method.

This study is motivated by the highly problematic nature of the accrual anomaly identified in Sloan (1996) as it suggests that the persistence of earnings attributable to the separate components of earnings; cash flow and accruals, are not fully understood by equity investors. Specifically, while cash flows provide greater information about the persistence of earnings than accruals, this is not evident in the pricing of earnings. This is inconsistent with the predictions of the efficient market hypothesis (Fama, 1991), and it is hence labeled the 'accrual anomaly'. Subsequent to Sloan (1996) a substantial empirical literature has developed evaluating 
the accrual anomaly. This has considered the sensitivity of the results to research design, and has considered variations in the definition of accruals, including accruals widely defined as all items on the balance sheet except cash (Richardson, Sloan, Soliman and Tuna, 2006), and more narrowly defined as only discretionary accruals (e.g., Beneish \& Vargus, 2002; Hribar, 2001; and Zach, 2003). Furthermore the possibility of the anomaly simply capturing variations in the riskreturn relationship has been addressed by Hirshleifer, Hou and Teoh (2006). It has also been found that the accrual anomaly is distinct from other anomalies such as the PEAD anomaly (Collins and Hribar, 2000) and the value glamour anomaly (Desai, Rajgopal \& Venkatachalam, 2004). Importantly, to date the accrual anomaly persists and there is no satisfactory theoretical explanation for the results obtained.

This study makes several contributions to the literature. First, evaluation of the accrual anomaly to date has largely been based upon United States data, and this paper provides a replication of the accrual anomaly in an alternative setting. ${ }^{1}$ This is considered relevant due to institutional differences between Australia and the United States, including the requirement in AASB 1026 Statement of Cash Flows for firms to report cash flows from operating activities calculated using the 'direct method'. Second, sensitivity analysis conducted on the research design will enable us to further evaluate whether the prior results are a consequence of design choices. A benefit of considering the anomaly within an Australian context is that it includes smaller firms in the study where the effects of the anomaly may be more pronounced.

Based on a sample of Australian firms over the period 1991 to 2005, while there is general support for the existence of the accruals anomaly in Australia there are a number of

\footnotetext{
${ }^{1}$ Exceptions are the studies of La Fond (2005) and Pincus, Rajgopaul and Venkatachalam, (2003) which provide an evaluation of the accrual anomaly across many countries, including Australia. However, a limitation of these studies is the sample selection procedure employed, and sample firms potentially not being representative of firms in countries other than the United States.
} 
idiosyncrasies in the results. First, there is evidence that in Australia investors underestimate the persistence of earnings. Second, there are greater errors in assessing the impact of cash flows on the persistence of earnings than accruals (i.e., a cash flow anomaly rather than an accruals anomaly). Third, returns to the hedged portfolio trading strategy are increasing over the three year period subsequent to portfolio formation. Analysis of these results, to date, indicates that they are primarily attributable to a limited number of firm year observations in the extreme positive tail of returns. Additionally, a range of sensitivity tests were undertaken to address the robustness of these results

The remainder of the paper is organized as follows. The next section of the paper reviews the prior literature research and outlines the hypotheses. Section three discusses the research design, while sample firms and descriptive statistics are outlined in section four. The primary results are presented in section five. Finally, the conclusions are provided in section six.

\section{Literature Review \& Hypotheses development.}

The provision of information for decision making has long been recognised as a function of accounting, and earnings is the measure most frequently identified as providing information about performance. ${ }^{2}$ Doubtless contributing to this view is the assertion by the FASB that earnings are a better indicator of the firms' ability to generate future cash flows than current period cash flows, and this is attributed to the application of accrual accounting. This view is shared by standard setters in Australia and internationally. The underlying argument is that earnings numbers prepared according to the dictates of accrual accounting enhance financial

\footnotetext{
${ }^{2}$ For example, Statement of Accounting Concepts (SAC) 2, Objectives of General Purpose Financial Reporting, and Framework for the Preparation and Presentation of Financial Statements.
} 
reporting and investor decision-making by better capturing increases (decreases) in resources controlled by the firm.

Empirical support for these propositions is provided in the first instance by studies evaluating the association between earnings and stock prices (e.g., Ball and Brown, 1968; and Easton and Harris, 1991), and then in studies contrasting earnings and cash flow measures of performance. Early studies simply compared earnings and cash flow measures (e.g., Bowen, Burgstahler and Daley, 1986; and Wilson, 1986), and evaluated the association between earnings, cash flow and stock returns (e.g., Bowen, Burgstahler and Daley, 1987; and Wilson, 1987). These provide evidence of earnings and cash flow measures of firm performance being significantly different, yet both associated with stock returns. However, their relative importance was not addressed. This was undertaken by Dechow (1994), who specifically addressed the question of whether earnings (i.e., cash flow and accruals) better captured firm performance than cash flow. Critically, support was found for the proposition that earnings contains incremental information content over cash flows, and that accounting accruals statistically enhance earnings as a performance measure.

While there is evidence of accruals statistically enhancing the relevance of earnings as a measure of performance, whether the implications of accruals for future earnings are fully understood by the market remains an issue. In addressing this issue Sloan (1996) first documents differing implications of cash flows and accruals for the persistence of earnings. This is not unexpected given the nature of accruals. However, there is evidence that this difference is not fully reflected in stock returns and thus not fully appreciated by the market. Based upon tests which infer from stock returns the expected impact of cash flows and accruals on the persistence of earnings, and by comparing stock returns across a hedge portfolio of high (low) accrual firms, 
Sloan finds that equity investors appear to overestimate the impact of accruals on the persistence of earnings and thus incorrectly price stocks in the extreme portfolios. This leads to the proposition that investors are fixated on earnings, which is inconsistent with the efficient market hypothesis, and is labeled the 'accrual anomaly'.

Subsequent to Sloan (1996) researchers have sought to determine whether the accrual anomaly is distinct from other capital market phenomena. For example Collins and Hribar (2000) considered whether the accrual anomaly is distinct from the Post Earnings Announcement Drift (PEAD) anomaly. They found that abnormal returns for hedge portfolios constructed with regard to both anomalies provided abnormal returns in excess of those arising from portfolios based upon either anomaly alone. On this basis they concluded that rather than being one phenomenon, they are distinct and independent of each other. Similarly, Desai, Rajgopal \& Venkatachalam (2004) evaluated the relation between the value-glamour anomaly and the accrual anomaly. They found only a partial match between the accrual anomaly and the value-glamour anomaly whereby stocks with high ratios of fundamentals to price (value stocks) and high accruals outperform stocks with correspondingly low fundamental to price (glamour stocks) and low accruals. Atwood and Xie (2005) and Dechow and Ge (2005) examined the relation between the accrual anomaly and the market mispricing of special items. Both provide evidence that suggests negative (positive) special items aggravate (relieve) the extent to which the market overprices accruals. However, while Dechow and Ge attribute their findings to psychological factors influencing investors, Atwood and Xie highlight the fact that while investors understand that negative special items are much less persistent than cash flow and 'non-special items' accruals, they still expect the negative effect to continue into the future at a higher level than what actually occurs. In contrast investors are more wary of positive special items and this enables them to be 
priced more accurately. Critically, there remains no satisfactory theoretical explanation for the accrual anomaly, with the results indicating that if anything, the market mispricing of special items, being the weaker anomaly, is an offshoot of the accrual anomaly.

As with other anomalies, considerable attention has been focused upon the aspects of research design concerned with the calculation of abnormal returns to identify a potential explanation of the result. This is a natural question given the expectation that if risk free returns are available they should be traded away. Mashruwala, Rajgopal and Shevlin (2004) consider possible impediments to the operation of arbitragers. They found that transaction costs, the cost of capital and risk all contribute to the anomaly not being traded away. However, Mashruwala et. al. do not explain away the accrual anomaly, they simply explain why it might not be traded upon. Hirshleifer, Hou and Teoh (2006) considered the potential for the abnormal portfolio returns to simply reflect risk, but were unable to find a significant association between the abnormal accrual returns and any measure of risk.

Attention has also been directed at the accruals on which the anomaly is based. Louis, Robinson and Sbaraglia (2006) examine if the accrual anomaly returns are driven by accrual disclosure. Although their results are mixed and potentially influenced by a degree of measurement error in some proxies, some evidence is provided that increasing disclosure prevents large price adjustments at the next period earnings announcement. On the basis that the extreme accruals on which portfolios are determined may simply be capturing earnings management, researchers have evaluated the sensitivity of the results to partitioning firms on the basis of abnormal or discretionary accruals. Xie (2001), Chan, Chan, Jegadeesh and Lakonishok (2001) and Defond \& Park (2001) all examine the influence abnormal accruals have on the accrual anomaly. They provide evidence that the use of abnormal accruals to construct the hedge 
portfolio generates higher abnormal returns than the returns generated by firms partitioned on the basis of accruals more generally. Furthermore, Chen and Cheng (2002) suggest that the mispricing of accruals is due to investors failing to appreciate the motivations of managers in managing earnings. However, a major limitation in these studies is the maintained assumption that accruals are being accurately decomposed into discretionary and non discretionary components. Dechow, Sloan and Sweeney (1995) suggest that this is problematic, particularly in firms reporting extreme performance.

In summary, the prior research has only been partially successful in explaining the accrual anomaly. However, the literature is focused almost entirely on the United States. Whilst exploratory international studies haven been undertaken (e.g., Pincus, Rajgopal and Venkatachalam, 2003; and LaFond, 2005) which indicate the accrual anomaly does exist internationally, it has not been comprehensively evaluated in other countries. Detailed consideration of the accrual anomaly in an Australian context is considered appropriate as this may provide insights into institutional and other factors giving rise to the anomaly.

Accordingly this suggests testing the following hypotheses within an Australian context. First, that due to the reversing nature of accruals, the extent of measurement difficulties that exist or the possibility that accruals may reflect earnings management, the accrual component of earnings has less implications for the persistence of earnings than the cash flow component.

\section{$H_{1}$ : $\quad$ The persistence of the earnings performance attributable to accruals is lower than the persistence of the earnings performance attributable to cash flow.}

Second, that the different implications for the persistence of earnings of the accrual and cash flow components is not fully understood, with investors overestimating the impact of accruals on the persistence of earnings. 
$\mathrm{H}_{2}$ : $\quad$ Investors tend to over anticipate the persistence of the earnings performance attributable to accruals and under anticipate the persistence of earnings performance attributable to cash flow.

Third, the markets failure to fully understand the impact of accruals on the persistence of earnings can be relied upon to form a trading strategy that generates abnormal returns for investors. In other words, the result is not only statistically significant, but also economically significant.

$H_{3}$ : $\quad$ An abnormal return may be earned by investing long in ASX listed companies with low levels of accruals and shorting ASX listed companies with high levels of accruals.

\section{Research Design}

Initially the focus of this paper is on the determination of whether the accrual anomaly exists in an Australian context. To determine this, the accrual anomaly study conducted by Sloan (1996) will be replicated using Australian data. Attention will then shift to the consideration of the sensitivity of this result to changes in the research design, including measurement of accruals, sample construction and portfolio construction.

\subsection{Primary Tests: Replication of Sloan in Australian context.}

Decomposition of Earnings into its components

Central to Sloan (1996) is the decomposition of earnings into the cash flow and accrual components to enable determination of the impact of the separate components on the persistence of earnings. In the prior literature this has been problematic due to the lack of cash flow data across sample periods, and cash flow has generally been determined by deducting accruals (estimated with balance sheet information) from earnings. However, there is evidence that accruals estimated in this manner are biased (e.g., Hribar \& Collins, 2002). Accordingly, rather 
than estimate cash flow and accruals with error, the sample period is restricted to years after 1991. ${ }^{3}$ AASB 1026 Statement of Cash Flows was issued in 1991, and requires the presentation of cash flow from operations under the direct method. It should be noted that Sloan focuses upon operating earnings, hence earnings are decomposed into cash and accrual components as follows:

$$
\text { Acc }_{\text {it }}=\text { EBIT }_{\text {it }}-\text { CFOBIT }_{\text {it }}
$$

Where:

EBIT $_{\text {it }} \quad$ : Earnings before tax, net interest, abnormal and significant items for firm $\mathrm{i}$ in period $t$

CFOBIT $_{\text {it }} \quad$ : Cash Flow from Operations from cash flow statement plus interest and tax for firm $i$ in period $t$

Acc $_{\text {it }} \quad:$ Accruals for firm $\mathrm{i}$ in period $\mathrm{t}$.

Persistence of cash flow and Accruals

Initially attention is directed towards the determination of whether the cash flow and accruals components of earnings have the same implications for the persistence of earnings $\left(\mathrm{H}_{1}\right)$. To establish a benchmark, earnings is regressed on lagged earnings (equation 2). Whether cash flow and accruals have different implications for earnings persistence is then evaluated by regressing the lagged components of earnings, on earnings (equation 3).

$$
\begin{array}{r}
\mathrm{EBIT}_{\mathrm{it}+1}=\alpha_{0}+\alpha_{1} \mathrm{EBIT}_{\mathrm{it}}+\varepsilon_{i t} \ldots \ldots \ldots . \\
\mathrm{EBIT}_{\mathrm{it}+1}=\gamma_{0}+\gamma_{1} \mathrm{Acc}_{\mathrm{it}}+\gamma_{2} \mathrm{CFOBIT}_{i t}+\varepsilon_{i t}
\end{array}
$$

An F-Test is used to test the equality of the coefficients (i.e., $\gamma_{1}=\gamma_{2}$ ) of the earnings components. For the accrual anomaly to exist in the form it is currently known, it is a necessary condition that cash flows have greater implications for the persistence of earnings than accruals.

\footnotetext{
${ }^{3}$ Although not strictly consistent with Sloan, sensitivity analysis of the results to this method of calculating accruals rather than the balance sheet estimation method of calculating accruals is undertaken and the results are broadly similar.
} 


\section{Mishkin Test}

Attention is then directed to whether the different implications of cash flows and accruals for earnings persistence are appreciated by investors $\left(\mathrm{H}_{2}\right)$. Consistent with Sloan this is evaluated using a test developed by Mishkin, which consists of the following rational pricing model:

$$
\left(r_{t+1}-r_{t+1} \mid \phi_{t}\right)=\beta\left(X_{t+1}-X_{t+1}^{e}\right)+\varepsilon_{t+1}
$$

Where:

$$
\begin{aligned}
& \mathrm{r}_{\mathrm{it}+1} \quad: \quad \text { Return to holding a security } \mathrm{i} \text { in period } \mathrm{t}+1 \\
& \mathrm{r}_{\mathrm{it}+1} \mid \Phi_{\mathrm{it}+1} \quad: \quad \text { The objective expectation of } \mathrm{r}_{\mathrm{it}+1} \text { conditional on } \Phi_{\mathrm{it}+1} \\
& \beta \quad \text { : A valuation multiplier } \\
& \mathrm{X}_{\mathrm{it}+1} \quad: \quad \text { A variable relevant to the pricing of a security in period } \mathrm{t}+1 \\
& \mathrm{X}^{\mathrm{e}}{ }_{\mathrm{it}+1} \quad \text { : The rational forecast of variable } \mathrm{X}_{\mathrm{it}+1} \text { at time } \mathrm{t} \\
& \varepsilon_{t+1} \quad \text { A disturbance with the property that } \mathrm{E}\left(\varepsilon_{t+1} \mid \Phi_{t}\right)=0
\end{aligned}
$$

Combining a first order auto regression of earnings with this rational pricing model tests whether investors fully understand the implications of the persistence of earnings and its components. This is reflected in the following systems of equations:

$$
\begin{array}{r}
\operatorname{EBIT}_{\mathrm{it}+1}=\alpha_{0}+\alpha_{1} \mathrm{EBIT}_{\mathrm{it}}+v_{i t} \ldots \ldots \ldots . . \\
\left(r_{t+1}-r_{t+1} \mid \phi_{t}\right)=\beta\left(\mathrm{EBIT}_{t+1}-\alpha_{0}-\alpha_{1}^{*} E B I T_{t}\right)+\varepsilon_{t+1}
\end{array}
$$

and

$$
\begin{gathered}
\text { EBIT }_{\mathrm{it}+1}=\gamma_{0}+\gamma_{1} \mathrm{Acc}_{\mathrm{it}}+\gamma_{2} \mathrm{CFOBIT}_{i t}+v_{i t} \ldots \ldots \ldots . \\
\left(r_{t+1}-r_{t+1} \mid \phi_{t}\right)=\beta\left(E \mathrm{EIT}_{t+1}-\gamma_{0}-\gamma_{1}^{*} \mathrm{ACc}_{t}-\gamma_{2}^{*} \mathrm{CFOBIT}_{t}\right)+\varepsilon_{t+1}
\end{gathered}
$$

To test for efficient market pricing we compare the coefficients from the rational pricing model with those from the first order auto regression. Consistent with $\mathrm{H}_{1}$ we expect the persistence implications of the earnings components in Australia to be comparable to the US, thus we expect 
the persistence implications of accruals to be less then the persistence implications of cash flows (i.e., $\gamma_{1}<\gamma_{2}$ ). Where the market is efficient, investors should identify correctly the difference in persistence of the earnings components (i.e., $\gamma_{1}^{*}<\gamma_{2}^{*}$ ), and the co-efficients across the equations should be similar (i.e., $\gamma_{1}{ }^{*}=\gamma_{1}$ and $\gamma_{2}{ }^{*}=\gamma_{2}$ ).

\section{Hedge Portfolio Return}

While the Mishkin test identifies whether the accrual anomaly exists in a statistical sense, it does not establish whether it is economically significant. To address this Sloan adopts two strategies. First, the construction of hedge portfolios whereby firms are partitioned into portfolios based on the signed accruals, and long positions are taken in firms with low accruals and short positions are taken in high accrual firms. Second, the estimation of Jensen alphas at the portfolio level using a time-series regression to compare returns across portfolios of firm. ${ }^{4}$ In this study the first approach will be relied upon as it requires less restrictive assumption.

The hedge portfolio abnormal return is calculated by subtracting the buy-hold return of a given firm from the buy-hold return of the value-weighted portfolio of firms to which that firm belongs. To ensure consistency with Sloan (1996), value weighted portfolios are constructed on the basis of size, where size is measured by the market value of equity. Returns are calculated three months from the end of the financial year to ensure sufficient time has passed for the financial reports to be released.

\subsection{Sensitivity Tests}

\footnotetext{
${ }^{4}\left(\mathrm{R}_{\mathrm{pt}}-\mathrm{R}_{\mathrm{jt}}\right)=\alpha_{\mathrm{p}}+\beta_{\mathrm{pt}}\left(\mathrm{R}_{\mathrm{mt}}-\mathrm{R}_{\mathrm{ft}}\right)+\varepsilon_{\mathrm{pt}}$
} 
A major objective of this paper is to determine whether changes to the research design contributed to the results. Accordingly a range of sensitivity tests are undertaken and are discussed below.

\section{Reported and Balance Sheet Estimation of Cash Flows from Operations}

In Sloan (1996) accruals are estimated from balance sheet information, whereas in this study cash flows are obtained from the cash flow statement and deducted from earnings to calculate accruals. This is possible due to the issuance of AASB 1026 Statement of Cash Flows in 1991 that requires firms to present cash flows from operations calculated by using the direct method. Unfortunately this requires restriction of the sample period to 1991 onwards. However, this provides us with a unique opportunity to examine the accrual anomaly with a slightly more reliable basis of calculating accruals than that used in prior United States studies. ${ }^{5}$ By comparing the two approaches to estimating accruals this paper proposes to assess whether errors generated in accrual estimation may be a determinant of the accrual anomaly.

For comparative purposes the Sloan (1996) calculated accruals are as follows:

$$
\operatorname{Acc}_{i t}=\left(\Delta C A_{i t}-\Delta \operatorname{Cash}_{i t}\right)-\left(\Delta C L_{i t}-\Delta S T D_{i t}-\Delta T P_{i t}\right)-D_{i t}
$$

Where

$\Delta \mathrm{CA}_{\mathrm{it}} \quad: \quad$ Change in current assets for firm $\mathrm{i}$ in period $\mathrm{t}$.

$\Delta$ Cash $_{\text {it }}$ : Change in cash and cash equivalents for firm $\mathrm{i}$ in period $\mathrm{t}$.

$\Delta \mathrm{CL}_{\text {it }} \quad$ : Change in current liabilities for firm $\mathrm{i}$ in period $\mathrm{t}$.

$\Delta \mathrm{STD}_{\mathrm{it}} \quad$ : Change in debt incurred in current liabilities for firm $\mathrm{i}$ in period $\mathrm{t}$.

$\Delta \mathrm{TP}_{\mathrm{it}} \quad: \quad$ Change in income taxes payable for firm $\mathrm{i}$ in period $\mathrm{t}$.

Depit $_{\text {it }} \quad$ : Depreciation and amortisation expense for firm $\mathrm{i}$ in period $\mathrm{t}$.

Cash flows are then determined as the residual component of earnings. All tests are repeated with this alternative determination of accruals.

\footnotetext{
${ }^{5}$ AASB 1026 requires firms to report direct cash flow from operations. SFAS No. 95 gives companies the choice of reporting direct cash flow from operations or indirect cash flow from operations. Most US companies choose to report operating cash flow using the indirect method (i.e., estimating operating cash flow from the balance sheet).
} 
Operating Profitability or Reported Profitability

A feature of Sloan (1996) is that in both the Mishkin tests and in the Hedge Portfolios, the focus is on operating performance, and the accounting variables are scaled by total assets. However, for evaluating the markets perception of the persistence of earnings the focus is upon equity returns.

The emphasis on operating performance and its decomposition into cash flow (CFOBIT) and accrual (Acc) components, scaled by total assets was followed due to persuasive arguments in the valuation literature for the exclusion of financing activities from business analysis. Furthermore, Penman (2001) illustrates that financing activities do not add value to a business and should be excluded from fundamental business valuations.

However, by comparing operating accounting returns with equity returns there is the potential for the results to be impacted by systematic differences in leverage, or changes in leverage. Accordingly, sensitivity testing is conducted with the accounting measures calculated including financing cash flows and accruals, and with all variables scaled by equity.

$$
\mathrm{OPAT}_{\text {it }}=\mathrm{CFO}_{\text {it }}-\mathrm{TAcc}_{\text {it }}
$$

Where:

OPAT $_{\text {it }} \quad$ : Operating profit after tax, but before abnormal and significant items for firm $i$ in period $t$

$\mathrm{CFO}_{\text {it }} \quad:$ Cash Flow from Operations from cash flow statement for firm $\mathrm{i}$ in period $\mathrm{t}$

TAcc $_{\text {it }} \quad$ : Accruals, including tax and financing accruals for firm $\mathrm{i}$ in period $\mathrm{t}$.

\section{Relative Accruals to Cash Flows Portfolio Construction}

In Sloan firms are partitioned for the hedge portfolio on the basis of the level of accruals (signed). Hedge portfolio gains may be reduced and subsequent tests of differences across the 
portfolios may lack power if the portfolio construction is noisy. In the event that it is not the signed level of accruals, but rather it is the significance of accruals relative to cash flow that determines income, an alternative partitioning of firms is suggested. Accordingly, hedge portfolios will be constructed on the basis of accruals relative to absolute cash flows, and the impact on hedge portfolio returns assessed.

\section{Profit / Loss Firms}

There is evidence of the relation between earnings and stock returns differing across profit and loss firms (e.g., Basu, 1997), and this doubtless reflects a lower persistence for losses (e.g., Klein and Marquardt, 2006). A further problem is the increasing incidence of loss firms (e.g., Elliot and Hanna, 1996) in recent times. Considering the fact the sample used in this paper consists of a more recent time period and reflecting the possibility that the result may be attributable to a differing persistence of earnings for profit and loss firms, the results are calculated separately for profit and loss firms.

\section{Non Mining Firms}

A large part of the sample firms in this paper are mining firms, and many of them are relatively small and infrequently traded. Reflecting the possibility that the result is a consequence of these firms, which are not representative of the aggregate market, the results are re-calculated after excluding mining firms from the sample. Mining firms are defined as any firm that falls into the adjusted CRIF-SPPR Past GICS industry category number ' 5 '. This category is adjusted to include all companies defined as mining companies under the old ASX industry codes. 


\section{Large / Small Firms}

Finally, consideration is given to the partitioning of firms on the basis of size to reflect the significant body of literature documenting size as a significant variable in empirical accounting studies. Specifically, reflecting the possibility that the anomaly resides predominantly in small firms where it is less able to be traded upon, the results are calculated for large and small firms separately.

\section{Data}

Sample firms for this study were chosen in the first instance from firms included on the CRIF Share Price and Price Relative Database (SPPR). The most recent version of SPPR provides monthly price data from December 1973 to December 2005, and an advantage of using this database for sample selection was the ability to track changes in ASX codes over that time period. Financial data was obtained from the Aspect Financial Database. Cash flow data is only available from 1991 onwards and this limits the sample to subsequent periods. This process identified a potential sample of 15,414 firm year observations.

This sample was reduced for firms not trading after 1991 (891 firm year observations), firms in the financial services sector for which accruals can not be reliably determined $(1,814$ firm year observations) and firms with duplicate records (348 firm year observations). This provided a sample of 12,358 firm year observations. Prior to testing, observations outside the $1^{\text {st }}$ and $99^{\text {th }}$ percentile were excluded, providing a maximum sample of 11,113 useable firm year observations. This was reduced as necessary by the data requirements of particular tests and the final sample for each test is outlined in the appropriate tables. ${ }^{6}$

\footnotetext{
${ }^{6}$ This was naturally reduced by the requirement for lagged values.
} 
Descriptive statistics for sample firms are contained in Table 2. In Panel A descriptive statistics are provided for variables scaled by lagged total assets. Notably mean (median) earnings are $-4.56 \%(2.76 \%)$ of total assets, indicating a significant number of firms are reporting losses and the sample is skewed by a few firms reporting large losses. The mean (median) value of accruals is $-1.33 \%(0.5 \%)$ of total assets. These results are broadly consistent with those provided in other studies of Australian firms over a similar period and there is nothing to indicate that the present sample is not representative.

In Panel B descriptive statistics are presented for each of the portfolios of firms upon which subsequent hedge returns will be calculated. This indicates that for the portfolio of lowest accrual firms the mean accrual was $-23.7 \%$, which compares with $+21.3 \%$ for the highest accrual firms. These values of accruals in relation to lagged total assets are extreme. The corresponding earnings values for the portfolios are $-28.4 \%$ and $0.8 \%$. These values are considerably lower than the results in Sloan ( $7 \%$ and $15 \%$ respectively), and it is likely that this is a consequence of the more recent time period (1962-1991 v's 1991 - 2005) and an increasing incidence of loss firms (Elliot \& Hanna, 1996). The proportionally higher number of small firms in Australia is also likely to be contributing not only to this, but also the relatively extreme values of accruals. In Sloan the mean value of accruals for the lowest accrual portfolio is only $-18 \%$, while for the highest accrual portfolio it is $15 \%$. This confirms the appropriateness of considering the sensitivity of the results to the partitioning of firms on the basis of profitability and size.

\section{Results - Primary Results}

5.1 The implications of accruals and cash flow for the persistence of earnings $\left(H_{1}\right)$ 
Attention is directed in the first instance towards determining whether accruals and cash flow have differing implications for future period earnings, with the results presented in Table 3. Panel A identifies the persistence of EBIT, and provides a benchmark for subsequent tests. Importantly, this identifies a significant relation between EBIT and future EBIT $\left(\alpha_{1}=0.6658\right.$, tstatistic $=76.9211)$ and the regression has an adjusted $R^{2}$ of $39.24 \%$. The co-efficient on EBIT $\left(\alpha_{1}\right)$ is lower than that reported by Sloan $(0.841)$ which is not surprising considering the differences in descriptive statistics identified above. Specifically, sample size (11,113 firm years versus 40,679 ) and the trading and reporting patterns of Australian firms are also likely to influence this result.

In Panel B the implications of accruals and cash flow for the persistence of earnings is considered. The co-efficients on Acc $\left(\gamma_{1}=0.6277, \mathrm{t}\right.$-stat $\left.=45.1581\right)$ and CFOBIT $\left(\gamma_{2}=0.8213\right.$, $\mathrm{t}$ stat $=66.8325)$ are both statistically significant, and the possibility that $\gamma_{1}=\gamma_{2}$ is rejected (F-stat $=$ 93.4190). ${ }^{7}$ Accordingly, consistent with Sloan there is support for $\mathrm{H}_{1}$ and accruals and cash flows having different implications for the persistence of earnings.

\subsection{Mishkin Test $\left(\mathrm{H}_{2}\right)$}

Having established that accruals and cash flows have different implications for the persistence of earnings, attention is directed towards $\mathrm{H}_{2}$ and determining whether these differences are fully understood by investors, with the results reported in Table 4 .

Whether the market accurately anticipates the persistence of earnings generally is considered first in Panel A. The coefficient $\alpha_{1}$ represents the actual persistence of earnings while

\footnotetext{
7 The co-efficients on Acc and CFOBIT are lower than those reported in Sloan, however the relativities are maintained. The negative intercept in both regressions is not characteristic of US data and is likely to be representative of the higher proportion of loss firms in more recent data samples (Elliot \& Hanna, 1996) and the smaller size of Australian firms.
} 
the coefficient $\alpha_{1}{ }^{*}$ represents the markets interpretation of the persistence of earnings. If the market accurately assesses the persistence of earnings the coefficients should be the same. However, this is not the case with $\alpha_{1}=0.6826$ and $\alpha_{1}{ }^{*}=0.5934$ (LRS=2.5364 and MSL=0.1112). Problematically, this is not consistent with the market accurately assessing the persistence of earnings and suggests that investors systematically underestimate the persistence of earnings. ${ }^{8}$ This result may raise questions in the interpretation of the results in Panel B.

The market interpretation of the implication of cash flow and accrual components for the persistence of earnings is presented in Panel B. Consistent with Sloan it is apparent that the markets interpretation of the implications of accruals for the persistence of earnings $\left(\gamma^{*}=0.6813\right)$ is higher than the actual implications of accruals for the persistence of earnings $\left(\gamma_{1}=0.6579\right)$. Likewise, the markets interpretation of the implications of cash flows for the persistence of earnings $\left(\gamma_{2}^{*}=0.6084\right)$ is lower than the actual implications of cash flows for the persistence earnings $\left(\gamma_{2}=0.8314\right)$. The $\mathrm{LRS}=10.6713$ and $\mathrm{MSL}=0.0048$ allows rejection of the null hypothesis of an efficient market, being $\gamma^{*}{ }_{1}=\gamma_{1}$ and $\gamma^{*}{ }_{2}=\gamma_{2}$. Whilst the LRS is not as strong as that reported by Sloan (180.91) it is significant at the $1 \%$ level and hence provides support for $\mathrm{H}_{2}$.

In summary, the implications of earnings components for future period earnings appear not to be fully appreciated. However, this result might be influenced by the market underestimating the persistence of earnings generally. While this general result is consistent with Sloan, it should be noted that this result is driven by misinterpretation of the persistence of cash flow rather than accruals. This may have consequences for the results from the hedged portfolio

\footnotetext{
${ }^{8}$ The difference in results could be attributed to the greater degree of variance and information asymmetry in the Australian data as the standard error on $\alpha_{1}{ }^{*}$ is roughly 7 times larger then its US counterpart (0.0683 v's 0.009 ).
} 
trading strategy where portfolio construction is premised on the mispricing of accruals rather than accruals.

\subsection{The hedged portfolio trading strategy $\left(H_{3}\right)$}

The accrual anomaly is further evaluated with a hedged portfolio trading strategy, and the results are presented in Table 5. This shows abnormal returns equal of $6.75 \%, 7.45 \%$ and $7.31 \%$ in three years subsequent to portfolio formation. These results are positive and significant, confirming $\mathrm{H}_{3}$ and showing that the accrual anomaly results in economically significant in Australia. Consistent with the expectation outlined above, we observe that the hedged portfolio trading strategy provides weaker abnormal returns in an Australian context than an in the United States. Interestingly and contrary to expectation, the abnormal returns from the trading strategy in Australia strengthen over time, which is inconsistent with the US results which fade from $10.4 \%$ in year 1 to an insignificant $2.9 \%$ in year 3 . Failure by the market to correct mispricing after subsequent earnings announcements is problematic.

Further analysis into the distribution of the size adjusted value weighted abnormal returns was undertaken and is presented graphically in Figure 1.The histogram shows a variation in the number of observations across the portfolios, particularly one and two, which reside outside the $21^{\text {st }}$ positive bin. This suggests that the observed abnormal returns are likely a consequence of a relatively few observations in the extreme positive tail. Review of these observations confirms that they are valid, and it is possible that further research into characteristics of these firms may identify why they are driving the results.

In conclusion, there is general support for the results provided by Sloan in an Australian context, although interesting it appears to be more of a cash flow anomaly rather than an accrual 
anomaly. Additionally, there is also evidence of the anomaly being driven by returns in the positive tail of the returns distributions.

\subsection{Sensitivity}

As outlined in section 3, a significant number of sensitivity tests were undertaken and the results for these tests are provided in the appendices. The results of these tests are discussed here.

\section{Balance Sheet Estimation of Accruals}

In the above tests cash flow was identified from the Statement of Cash Flows, and accruals were determined by deducting cash flows from earnings. This contrasts with the process followed in Sloan whereby accruals were estimated from balance sheet information, and deducted from earnings to calculate cash flows. To determine how this impacted the results and whether this contributed to the variation in results, all tests were repeated with this alternative determination of accruals (unreported, available from authors).

The first notable impact on the results of this alternative measurement of accruals appeared in the descriptive statistics where mean accruals increased materially in comparison with the median. This is suggestive of an increasing skew towards positive accruals which was captured by an increase in mean accruals for the high accrual portfolio to $86 \%$ of total assets. This impact is expected given the evidence provided in the earnings management literature of the consequences of estimating accruals from balance sheet information (e.g., Hribar and Collins, 2002).

In tests of persistence, the coefficients on accruals and cash flow which measure the persistence of earnings attributed to the earnings components, have dropped substantially 
( 0.6277 to 0.4315 and 0.8213 to 0.5521 respectively), and is likely a consequence of the error in the estimation of accruals (and cash flows). Notwithstanding, the coefficient on accruals and cash flow are significantly different $(\mathrm{F}$-stat $=152.1)$ and the co-efficient on cash flow is higher than that for accruals. This indicates that while the balance sheet method introduces error into the estimation of accruals and cash flow, there is still support for $\mathrm{H}_{1}$.

The implications of error in estimating accruals are further evidenced in tests where the persistence of earnings components implied by share prices is evaluated. Whilst coefficient estimates are lower than those outlined in the primary results, it is notable that the markets estimate of earnings persistence attributable to accruals $\left(\gamma_{1}{ }^{*}=0.0646\right)$ is not statistically different from zero. This is far less then the actual implications of accruals for earnings persistence and suggests that the market estimates of the implications of accruals for the persistence of earnings are understated rather than overstated. Consistent with the previously reported results, the implications of the persistence of cash flow for future period earnings is understated. Finally, given the disparity in the coefficients on accruals (i.e., $\gamma_{1}$ and $\gamma_{1}{ }^{*}$ ) the equality of the coefficients can be easily rejected, although the understatement of the persistence implications of accruals is inconsistent with that predicted in $\mathrm{H}_{2}$.

The hedged portfolio trading strategy fails to yield significant abnormal returns in year $\mathrm{t}+1$, however these do arise in subsequent years. Accordingly, there is little evidence of economically significant returns that can be attributed to investing with an accruals strategy. This may have been a consequence of errors in portfolio construction arising from errors in accruals measurement. 
In summary, it is likely that the estimation of accruals from balance sheet information introduced error in the estimation of accruals, and the results are generally less supportive of the accrual anomaly than those in the primary tests. This is likely a more significant problem for studies using Australian data where sample firms are smaller and the errors from balance sheet estimation of accruals are likely more pronounced.

\section{Operating Profitability or Reported Profitability}

Addressing the issue of comparing firm based accounting returns with equity based price returns, tests were repeated considering accounting returns to equity holders (unreported, available from authors).

From the descriptive statistics it is notable that there is a larger variation in the variables, evidenced by greater standard errors, and more extreme maximum and minimum values. The earnings and accruals variables exhibit a stronger positive relation, and cash flow and accruals exhibit a stronger negative relation. Likely reflecting this greater variability the persistence of earnings, and the implications of cash and accrual components of earnings for the persistence of earnings, evidenced by the co-efficients on $\alpha_{1}$ and $\gamma_{1}$ and $\gamma_{2}$, are lower than in the primary results (i.e., 0.5064 v $0.6658,0.3958$ v 0.6277 and 0.5608 v 0.8213 respectively). However, the coefficients on accruals and cash flows are significantly different as predicted in $\mathrm{H}_{1}$.

An issue in the primary tests was the market underestimating the persistence of earnings. When this alternative accounting return measure was used the actual persistence of earnings and the persistence implied by share prices are much closer $\left(\alpha_{1}=0.5195\right.$ and $\left.\alpha_{1}{ }^{*}=0.4844\right)$ which is more consistent with an efficient market than the results in the primary results. This makes interpretation of the results in Panel B much easier. Importantly the coefficient on $\gamma_{1}^{*}$ is greater 
than that on $\gamma_{1}(0.5853 \mathrm{v}$ 0.3562) which is consistent with the market overestimating the persistence of accruals, while the coefficient on $\gamma_{2}^{*}$ less than that on $\gamma_{2}$ which suggests that the market underestimates the persistence of cash flows. These results are consistent with $\mathrm{H}_{2}$ and are stronger than those in the primary analysis.

However, while it appears from the above that the market incorrectly assesses the implications of cash flow and accrual components for the persistence of earnings, with the hedged portfolio trading strategy there is no evidence of significant abnormal returns. Interestingly, there are significant positive returns in portfolio five $(8.2 \%$ and $7.7 \%$ in $\mathrm{t}+1$ and $\mathrm{t}+2$ respectively) and in portfolio one $(8.8 \%$ and $8.4 \%$ in $\mathrm{t}+1$ and $\mathrm{t}+2$ respectively), with these cancelling out in the hedge portfolio.

In summary with accounting data adjusted for financial accruals and cash flows there is evidence of the accruals anomaly in the implied persistence of earnings, but this does not extent to the generation of abnormal returns.

\section{$\underline{\text { Accruals Relative to Cash Flow Portfolio Construction }}$}

In the primary tests portfolios are constructed on the basis of the magnitude of accruals, which is likely to condition sample firms of the basis of accruals and earnings. To address this sample firms where partitioned on the basis of accruals relative to cash flows. Accordingly, the focus of this sensitivity test is the result of the hedged portfolio trading strategy.

While there was considerable variation in the scaling variable, however, was much less variation in mean accruals across the portfolios. This suggests that many of the firms previously identified as having large accruals are also reporting large cash flows, and confirms the possibility of an income effect in the primary results. 
As portfolio construction has separated firms into high/low accruals portfolios the persistence of earnings and components of earnings are highest in the middle portfolios. For example in portfolios two and three the adjusted $\mathrm{R}^{2}$ were 0.5061 and 0.4168 and the persistence of earnings is 0.8216 and 0.8911 respectively. In comparison, in the extreme portfolios on which the hedged portfolio is based, there in much lower persistence.

The hedged portfolio trading strategy however fails to generate a significant return in year $\mathrm{t}+1$. However, somewhat problematically there are abnormal returns in year $\mathrm{t}+2$ and $\mathrm{t}+3$. This is consistent with either error in this portfolio construction eliminating the accrual anomaly, or alternatively bias is the original portfolio construction driving the anomaly result.

\section{$\underline{\text { Profit / Loss Firms }}$}

Partitioning sample firms into profit/loss firms is aimed at determining the impact that sample characteristics can have on the accrual anomaly. From the descriptive statistics it is evident that the maximum values for Cash Flow and Accruals for the entire sample are located within the profit sub-sample and the minimum values are located in the loss sub-sample. Additionally the mean (median) firm size (log of market capitalisation) is considerably lower for the loss firms, 16.29 (16.09) compared to profit firms, 18.28 (18.17). The differences are even more pronounced when firms are allocated to accrual portfolios.

As can be expected, the persistence of earnings, be it attributable to cash flows, accruals or earnings, is markedly less for loss firms then for profit firms. This is understandable and predictable as it is known that a company making a loss must reverse its performance at some stage in the future or experience distress. For both loss and profit firms the persistence of earnings attributable to accruals is less then that attributable to cash flow. 
In tests of how investors determine the impact of accruals and cash flows on earnings persistence it is apparent that investors underestimation of earnings persistence most for profit firms, but loss firms are more likely to be responsible for the accrual anomaly as the coefficient on accruals, $\left(\gamma_{1}{ }^{*}=0.46093\right)$, is overestimated and the coefficient on cash flow, $\left(\gamma_{2}{ }^{*}=0.6096\right)$, underestimated. Consistent with this, the abnormal returns are meaningfully higher for loss firms $(13 \%, 12.21 \%$ and $-0.7 \%)$ compared to profit firms $(8.89 \%, 3 \%$ and $-0.08 \%)$. Not surprisingly, the results for loss firms are driven by negative returns in portfolio five and the results for profit firms are driven by positive returns in portfolio one.

In conclusion, it is more likely that the accrual anomaly resides in small, probably loss making firms.

\section{$\underline{\text { Non Mining Firms }}$}

The exclusion of miners is an exploratory analysis into the characteristics of firms in the extreme portfolios and was considered important in analyzing firm and sample characteristics which are known to be unique to Australian data. Firms are classified as mining firms on the basis of the ASPECT database industry code, where firms are excluded if they have a Past GICS code or equivalent of 5 .

As expected the removal of mining firms eliminated a mainly small firms and this was reflected in changes in the descriptive statistics. Removing mining firms from the sample strengthened the results of the persistence regressions, and essentially reflects the fact that omitting mining companies has reduced the sample exposure to firms which are generally higher risk and more volatile than firms in other industries. 
However, the results are largely unchanged from those in the primary rests, where the market underestimates the persistence of earnings, attributing earnings with a persistence of $0.5914\left(\alpha_{1}^{*}\right)$ compared to the actual persistence of $0.7221\left(\alpha_{1}\right)$. Regarding earnings components, the market significantly overestimates the persistence of earnings attributable to accruals $\left(\gamma_{1}{ }^{*}=\right.$ $0.7260)$ and underestimates the persistence of earnings attributable to cash flow $\left(\gamma_{2}{ }^{*}=0.5253\right)$. Further, abnormal returns from the hedge portfolio of $7.49 \%, 6.56 \%$ and $-0.02 \%$ are generated in the years subsequent to portfolio construction, although they are significant in the first year only. In conclusion it does not appear that the accrual anomaly result is driven by mining firms.

\section{Conclusion}

The provision of information for decision making is well recognised as a function of accounting, and the performance measure commonly identified as best satisfying this function is earnings rather than cash flows. Sloan (1996) provides evidence that cash and accrual components of earnings have different implications for the persistence of earnings and that this is not understood by investors. Thus systematic mispricing of accruals occurs which creates the opportunity to earn abnormal hedge portfolio returns. The objectives of this paper are twofold. First, to provide evidence on whether the results in Sloan are generalisable to an Australian context. Second, to further investigate whether the accrual anomaly is a consequence of research design.

The replication tests conducted in this paper confirm the existence of the accrual anomaly in Australia, albeit in a weaker sense than it is known in the US. While there is general support for the existence of the anomaly in Australia there are a number of idiosyncrasies in the results. First, there is evidence that in Australia investors underestimate the persistence of earnings. 
Second, there are greater errors in assessing the impact of cash flows on the persistence of earnings than accruals (i.e., a cash flow anomaly rather than an accruals anomaly). Third, returns to the hedged portfolio trading strategy are increasing over the three year period subsequent to portfolio formation. Analysis of these results indicates that they are primarily attributable to a limited number of firm year observations in the extreme positive tail of returns.

Additionally, a range of sensitivity tests were undertaken to address the robustness of these results. These suggest that the results are sensitive to the method used to estimate accruals, the choice of accounting earnings measures, and the basis of portfolio construction. These suggest potential bases for the further evaluation of the accrual anomaly. 


\section{References}

Ali , Hwang and Trombley, 2001. "Accruals and future stock returns: Tests of the naive investor hypotheses."

Bath \& Hutton, 2001. “Financial Analysts and the pricing of Accruals.” Working Paper.

Chambers, D., 2005. “Earnings persistence and accrual anomaly.” Working Paper. University of Kentucky.

Chan, Chan, Jegadeesh and Lakonishok, 2001. "Earnings quality and stock returns: The evidence from accruals."

Chen, X., Cheng, Q., 2002. "Abnormal accrual-based anomaly and managers motivation to record abnormal accruals.” Working Paper. University of Wisconsin-Madison

David, L., Richardson, S., 2004. “Fees paid to audit firms, accrual choices and corporate governance."

Dechow, P., Ge, W., 2005. "The persistence of earnings and cash flows and the role of special items: Implications for the accrual anomaly”. Working Paper. University of Michigan.

Dechow, P., Richardson, S., Sloan, R., 2005. "The persistence and Pricing of the Cash Component of Earnings.” Working Paper. University of Pennsylvania.

Desai, H., Rajgopal, S., Venkatachalam, M., 2004. "Value-glamour and Accruals mispricing: One Anomaly or two?” The Accounting Review. Vol. 79. No. 2. Pp 355-385

Fairfield, Whiseant and Yohn, 2003. "Accrued earnings and growth: Implications for future profitability and market mispricing”

Fama, E. F., 1991. “Efficient Capital Markets: II.” Journal of Finance. Vol. 46 Issue 5, p15751617.

Gu, Z., Jain, R., 2006. “Can the accrual anomaly be explained away by operating cash flows: a component level analysis.” Working Paper. Carnegie Mellon University.

Hirshleifer, D., Hou, K., Teoh, S., 2006. “The accrual anomaly: Risk or mispricing?” Working Paper. Ohio State University.

Hribar, 2001. “The market pricing of components of accruals” Working Paper.

Atwood, T., Xie, H., 2005 “The market mispricing of special items and Accruals: One anomaly or two?" Working Paper. University of Illinois. 
LaFond, R., 2005. "Is the accrual anomaly a global anomaly?" Working Paper. MIT Sloan School of Management.

Louis, H., Robinson, D., Sbaraglia, A., 2006. "An integrated analysis of the association between accrual disclosure and the abnormal accrual anomaly." Working Paper. Pennsylvania State University.

Lyon, Barber, Tsai, 1999. "Improved methods for tests of long-run abnormal stock returns."

Mashruwala, C., Rajgopal, S., Shevlin, T., 2004. "Why is the accrual anomaly not arbitraged away?” JAE 42? 2006?. University of Washington.

Pincus, Rajgopal and Venkatachalam, 2003. "The accrual anomaly: International evidence." Working Paper.

Thomas \& Zhang, 2001. "Inventory changes and future returns.” Working Paper.

Collins, D., Hribar, P., 2000. "Earnings based and accrual based anomalies: One effect or two?” Working Paper. University of Iowa.

Richardson, S., Sloan, R., Soliman, M., Tuna, I,. 2006. "Information in accruals about the quality of earnings." The Accounting Review. Vol. 81 No. 3.

Xie, H., 2001. "The mispricing of abnormal accruals.” The Accounting Review. Vol. 76. No. 3.

Zach, T., 2003. "Inside the accrual anomaly” Working Paper. Washington University. 
Figure 1

Size Adjusted Value Weighted Abnormal Return Histogram

Figure 1.

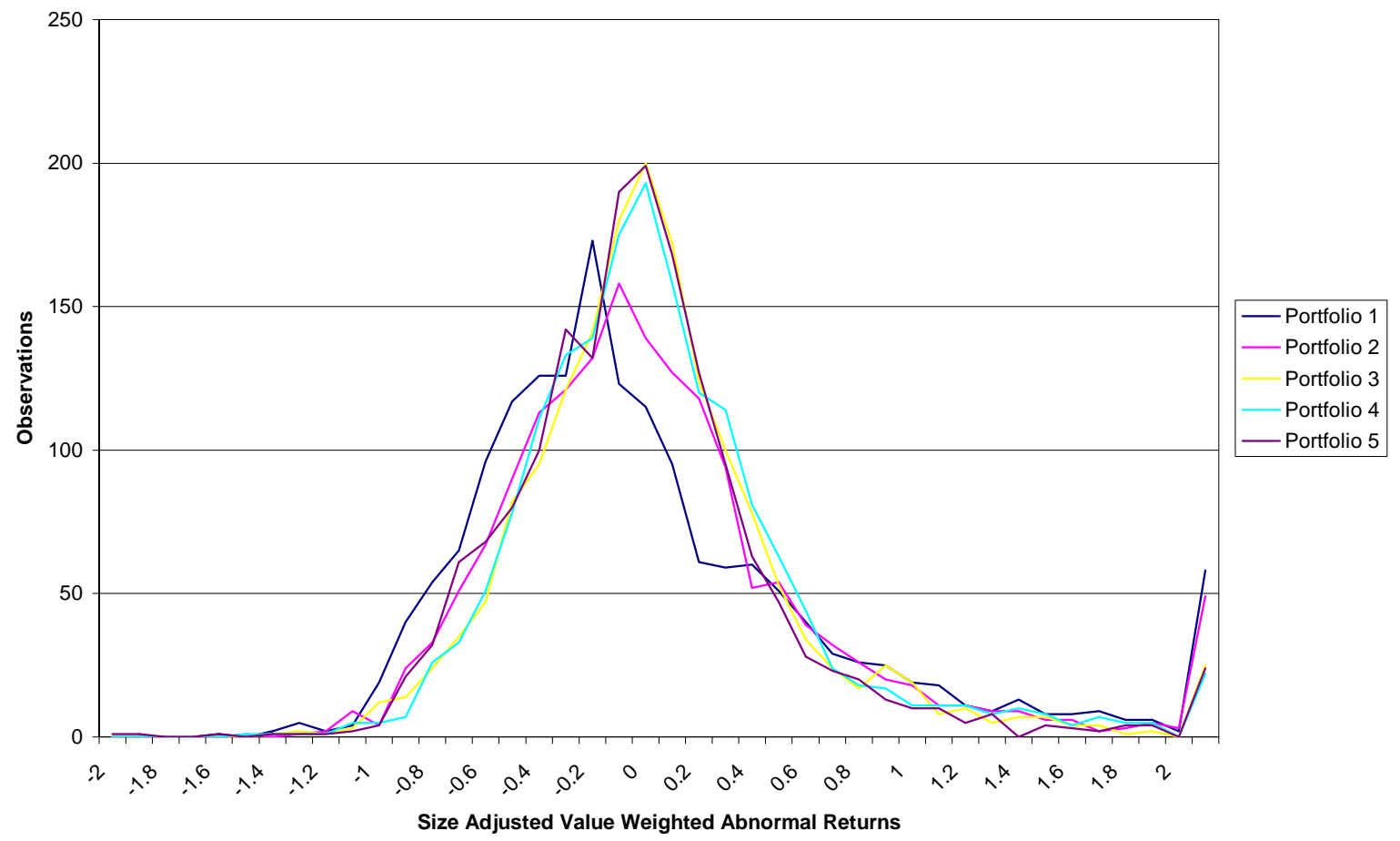




\section{Table 1}

\section{Sample Identification}

\begin{tabular}{|lr|}
\hline Full Aspect Database as at November 2005 & 23587 \\
Removal of companies whose details fail to match between SPPR- & -8173 \\
Total companies with available data in SPPR-CRIF and Aspect & 15414 \\
Deduct companies that do not trade after 1991 & -894 \\
Deduct companies in banking, finance and insurance industries & -1814 \\
Exclude duplicate records & -348 \\
Total Firm Years & 12358 \\
Firms without Total Asset Details & -997 \\
Outliers & 248 \\
Total Useable Data & 11133 \\
\hline $\begin{array}{l}\text { Number of observations for Persistence Testing of Earnings } \\
\text { Number of observations for Persistence Testing of Components of } \\
\text { Earnings }\end{array}$ & 9162 \\
Number of observations used in Mishkin Test of Earnings & 9020 \\
Number of observations used in Mishkin Test of Components of & 7256 \\
Earnings & \\
Average number of observations per portfolio in the Hedge Return & 7158 \\
Test for year one & \\
Number of observations used in the Hedge Return Test for year one. & \\
\hline
\end{tabular}

Notes

1 The databases were matched by ensuring observations in each database with identical ASX ticker codes had an observed trade date in Aspect between the list and delist dates recorded for the company in CRIF.

2 AASB XYZ, which requires companies to report a Statement of Cash Flow, was enforced from 30th June 1991.

3 Banking, Finance and Insurance companies are excluded from the sample to ensure an accurate replication of Sloan (1996). The argument for excluding these companies is because they arguably have little or no operating accruals.

4 Outliers were classified as observations outside the 1st and 99th percentiles.

Total number of abnormal return observations for Hedge Return Test divided by the

5 five portolios. 
Table 2

Descriptive statistics of earnings, components of earnings and firm characteristics of a sample of Australian firms between 1991 and 2006, excluding outliers beyond the 1st and 99th percentile.

\begin{tabular}{|lrrrrrr|}
\hline \multicolumn{7}{c|}{ Panel A: Variables Scaled by Total Assets } \\
\hline & $\mathrm{N}$ & Mean & Std Error & Median & Minimum & Maximum \\
EBIT & 11133 & -0.0456 & 0.2671 & 0.0276 & -1.9558 & 0.3557 \\
CFOBIT & 11133 & -0.0332 & 0.1897 & 0.0036 & -1.3618 & 0.3856 \\
Acc & 11133 & -0.0133 & 0.1671 & 0.0054 & -1.1195 & 0.4966 \\
& & & & & & \\
Total & & & & & & \\
Assets & & & & & & \\
$(\$ 000 ’ s)$ & 11133 & 377,055 & $1,084,249$ & 35,721 & & $9,297,500$ \\
\hline
\end{tabular}

\begin{tabular}{|lcrrrr|}
\hline \multicolumn{5}{|c|}{ Panel B: Mean values of Scaled Variables for Lowest to Highest Accrual Portfolio } \\
\hline & Lowest & 2 & 3 & 4 & Highest \\
& & & & & \\
EBIT & -0.2844 & -0.0311 & 0.0367 & 0.0634 & 0.0088 \\
CFOBIT & -0.0668 & 0.0051 & 0.0185 & -0.0128 & -0.1711 \\
Acc & -0.2307 & -0.0335 & 0.0186 & 0.0776 & 0.2134 \\
& & & & & \\
Size & 16.5650 & 17.2728 & 18.1795 & 17.9129 & 16.8380 \\
\hline
\end{tabular}

Where:

EBIT Reported earnings before tax, abnormals/significant items and net interest (interest revenue less interest expense)

CFOBIT Net cash flow from operations from cash flow statement adjusted for net interest and tax paid.

ACC EBIT - CFOBIT

SIZE The natural Log of the market value of common equity measured at fiscal year end 


\section{Table 3}

Results from Ordinary Least Squares Regression of Future Earnings on Earnings and of Future Earnings on the Components of Current Earnings for sample of Australian firms between 1991 and 2006.

\begin{tabular}{|c|c|c|c|c|c|c|}
\hline \multicolumn{7}{|c|}{ Panel A: Mishkin Test of markets ability to determine the persistence of earnings } \\
\hline \multicolumn{7}{|c|}{$\mathrm{EBIT}_{\mathrm{t}+1}=\alpha_{\mathrm{o}}+\alpha_{1} \mathrm{EBIT}_{\mathrm{t}}+\varepsilon_{\mathrm{t}+1}$} \\
\hline & Sloan & $\begin{array}{l}\text { Co- } \\
\text { efficient }\end{array}$ & Std Error & t-stat & p-value & \\
\hline$\alpha_{0}$ & 0.015 & -0.0195 & 0.0021 & -9.0499 & 0.0000 & *** \\
\hline$\alpha_{1}$ & 0.841 & 0.6658 & 0.0086 & 76.9211 & 0.0000 & *** \\
\hline Adjusted $\mathrm{R}^{2}$ & & 0.3924 & & & & \\
\hline
\end{tabular}

\begin{tabular}{|c|c|c|c|c|c|c|}
\hline \multicolumn{7}{|c|}{ Panel B: Future Earnings on Components of Current Earnings } \\
\hline \multicolumn{7}{|c|}{$\mathrm{EBIT}_{\mathrm{t}+1}=\gamma_{\mathrm{o}}+\gamma_{1}$ Accruals $_{\mathrm{t}}+\gamma_{2} \mathrm{CFO}_{\mathrm{t}}+\varepsilon_{\mathrm{t}+1}$} \\
\hline & Sloan & $\begin{array}{l}\text { Co- } \\
\text { efficient }\end{array}$ & Std Error & t-stat & p-value & \\
\hline$\gamma_{0}$ & 0.011 & -0.0180 & 0.0021 & -8.6329 & 0.0000 & $* * *$ \\
\hline$\gamma_{1}$ & 0.765 & 0.6277 & 0.0139 & 45.1581 & 0.0000 & $* * *$ \\
\hline$\gamma_{2}$ & 0.855 & 0.8213 & 0.0123 & 66.8325 & 0.0000 & $* * *$ \\
\hline Adjusted $\mathrm{R}^{2}$ & & 0.417 & & & & \\
\hline F-test: $\gamma_{1=} \gamma_{2}$ & & 614.01 & & 109.78 & 0.0000 & \\
\hline
\end{tabular}

All Variables as previously defined
$* * *$
Two tailed t-test significant at $1 \%$ level
** $\quad$ Two tailed t-test significant at 5\% level
* $\quad$ Two tailed t-test significant at $10 \%$ level 


\section{Table 4}

Results from Nonlinear Generalised Least Squares Estimation of the Stock Price Reaction to Information in Current Earnings and equal weighted al returns.

\begin{tabular}{|c|c|c|c|c|c|c|}
\hline \multicolumn{7}{|c|}{ Panel A: Future Earnings on Current Earnings } \\
\hline \multicolumn{7}{|c|}{$\mathrm{EBIT}_{\mathrm{t}+1}=\alpha_{\mathrm{o}}+\alpha_{1} \mathrm{EBIT}_{\mathrm{t}}+\varepsilon_{\mathrm{t}+1}$} \\
\hline \multicolumn{7}{|c|}{ Abnormal return $_{\mathrm{t}+1}=\beta\left(E B I T_{\mathrm{t}+1}-\gamma_{0}-\gamma_{1}^{*} E B I T_{t}\right)+\varepsilon_{\mathrm{t}+1}$} \\
\hline & Sloan & $\begin{array}{r}\text { Co- } \\
\text { efficient }\end{array}$ & Std Error & t-stat & p-value & \\
\hline$\alpha_{1}$ & 0.841 & 0.6826 & 0.0091 & 74.7504 & 0.0000 & $* * *$ \\
\hline$\alpha_{1}^{*}$ & 0.84 & 0.5934 & 0.0683 & 8.6808 & 0.0000 & $* * *$ \\
\hline$\beta$ & 1.92 & 0.5793 & 0.0509 & 11.3682 & 0.0000 & $* * *$ \\
\hline & cy: & $\alpha_{1=} \alpha_{1}^{*}$ & & & & \\
\hline & & 2.5364 & & & & \\
\hline $\mathrm{Ma}$ & evel & 0.1112 & & & & \\
\hline
\end{tabular}

\begin{tabular}{|c|c|c|c|c|c|c|}
\hline \multicolumn{7}{|c|}{ Panel B: Future Earnings on Current Earnings } \\
\hline \multicolumn{7}{|c|}{$\mathrm{EBIT}_{\mathrm{t}+1}=\gamma_{\mathrm{o}}+\gamma_{1}$ Accruals $_{\mathrm{t}}+\gamma_{2} \mathrm{CFO}_{\mathrm{t}}+\varepsilon_{\mathrm{t}+1}$} \\
\hline \multicolumn{7}{|c|}{ Abnormal return $_{\mathrm{t}+1}=\beta\left(\right.$ EBIT $_{\mathrm{t}+1}-\gamma_{0}-\gamma_{1}^{*}$ Accruals $_{t}-\gamma_{2}^{*}$ CFO $\left._{\mathrm{t}}\right)+\varepsilon_{\mathrm{t}+1}$} \\
\hline & Sloan & $\begin{array}{r}\text { Co- } \\
\text { efficient }\end{array}$ & Std Error & t-stat & p-value & \\
\hline$\gamma_{1}$ & 0.765 & 0.6579 & 0.0151 & 43.5283 & 0.0000 & $* * *$ \\
\hline$\gamma_{1}{ }^{*}$ & 0.911 & 0.6813 & 0.1068 & 6.3774 & 0.0000 & $* * *$ \\
\hline$\gamma_{2}$ & 0.855 & 0.8314 & 0.0131 & 63.5846 & 0.0000 & $* * *$ \\
\hline$\gamma_{2}^{*}$ & 0.826 & 0.6084 & 0.0938 & 6.4851 & 0.0000 & $* * *$ \\
\hline$\beta$ & 1.894 & 0.6282 & 0.0525 & 11.9653 & 0.0000 & $* * *$ \\
\hline & ncy: & $\gamma_{1}=\gamma_{1}$ & and $\gamma_{2}=\gamma_{2}{ }^{*}$ & & & \\
\hline & & & 10.6713 & & & \\
\hline $\mathrm{Ma}$ & level & & 0.0048 & & & \\
\hline
\end{tabular}


Where:

Abnormal Return Equal weighted size adjusted buy hold abnormal returns

All other variables as previously defined
$* * *$
$* *$
Two tailed t-test significant at 1\% level
$*$
Two tailed t-test significant at 5\% level
Two tailed t-test significant at 10\% level 


\section{Table 5}

Results of hedge portfolio trading strategy; Time series means of Equal Weighted, Size Adjusted, Buy Hold Abnormal Returns. (T-statistics in italics)

\begin{tabular}{|c|c|c|c|c|c|c|c|}
\hline \multirow{2}{*}{$\begin{array}{l}\text { Portfolio } \\
\text { Accrual } \\
\text { Ranking }\end{array}$} & \multirow{2}{*}{$\begin{array}{l}\text { Obs. in } \\
\text { portfolio }\end{array}$} & \multicolumn{6}{|c|}{ Size adjusted equal weighted abnormal returns } \\
\hline & & Year $\mathrm{t}+1$ & & Year $\mathrm{t}+2$ & & Year $\mathrm{t}+3$ & \\
\hline \multirow[t]{2}{*}{ Lowest (1) } & 1684 & 0.0311 & & 0.0441 & & 0.0498 & \\
\hline & & 1.2744 & & 1.6126 & * & 1.2467 & \\
\hline \multirow[t]{2}{*}{2} & 1651 & 0.0683 & & 0.0625 & & -0.0091 & \\
\hline & & 2.5085 & *** & 2.0729 & ** & -0.4306 & \\
\hline \multirow[t]{2}{*}{3} & 1685 & 0.0244 & & 0.0110 & & 0.0329 & \\
\hline & & 1.5293 & & 0.6785 & & 1.5736 & \\
\hline \multirow[t]{2}{*}{4} & 1748 & 0.0282 & & 0.0262 & & 0.0330 & \\
\hline & & 2.0503 & ** & 1.4125 & & 1.7453 & * \\
\hline \multirow[t]{3}{*}{ Highest (5) } & 1623 & -0.0365 & & -0.0304 & & -0.0233 & \\
\hline & & -1.7050 & * & -1.4670 & & -1.1340 & \\
\hline & & 0.0244 & & 0.0110 & & 0.0329 & \\
\hline \multirow[t]{2}{*}{ Hedge Strategy ${ }^{\# \#}$} & & 0.0675 & & 0.0745 & & 0.0731 & \\
\hline & & 2.0823 & ** & 2.171283 & ** & 1.6272 & * \\
\hline
\end{tabular}

Where:

\# Portfolios are formed by assigning firms into quintiles based on signed accruals in year $\mathrm{t}$

\#\# The hedge return is calculated by taking a long position in the lowest accrual portfolio (1) and a short position in the largest accrual portfolio (5)

*** $\quad$ Two tailed t-test significant at $1 \%$ level

** $\quad$ Two tailed t-test significant at $5 \%$ level

* Two tailed t-test significant at $10 \%$ level 